\title{
TEMPAT SINGGAH DUKUH ATAS STEPOVER PLACE
}

\author{
Marseno Sanjaya ${ }^{1)}$, Sutarki Sutisna ${ }^{2)}$ \\ 1)Program Studi S1 Arsitektur, Fakultas Teknik, Universitas Tarumanagara, marsenosanjaya20@gmail.com \\ 2)Program Studi S1 Arsitektur, Fakultas Teknik, Universitas Tarumanagara, sutarkis@gmail.com
}

\begin{abstract}
Abstrak
Berdasarkan data PT Kereta Commuter Indonesia $(\mathrm{KCl})$ jumlah penumpang KRL sepanjang 2017 mencapai 315,8 juta penumpang naik 12,55\% dari sebelumnya dan akan mengalami peningkatan setiap tahunnya. Dengan jumlah ini maka diketahui bahwa komuter juga mengalami peningkatan. Daerah yang memiliki akses yang mudah untuk transportasi umum dan strategis berada di pusat bisnis Jakarta yaitu Dukuh Atas. Dukuh atas juga merupakan daerah dengan penduduk commuter yang besar. Setiap hari kaum komuter di Indonesia menghabiskan 2 per 3 dari waktunya hanya untuk menunggu dan ada pengulangan yang terjadi. hal ini menyebabkan hal seperti ketidakperhatian individu terhadap kesehatan, dunia sosial dan juga tingkat stress yang tinggi .Oleh karena itu, dengan adanya jumlah penumpang yang terus meningkat dan kawasan yang sesuai dapat diciptakannya third place yaitu suatu tempat di antara first place dan second place yang mendorong manusia untuk membangun komunitas, kesetaraan, dan juga rutinitas dalam hal yang bersifat positif.Untuk itu, diperlukan sebuah tempat untuk singgah agar dapat meningkatkan produktivitas dan juga menghilangkan rasa jenuh yang timbul akibat pengulangan yang terjadi. Maka itu dibangunlah sebuah tempat yang memiliki program seperti tempat tidur, tempat untuk bercengkrama dan juga ruang hijau.Bangunan ini juga mempunyai ruang untuk informasi tiket yang berintegrasi langsung dengan Stasiun Dukuh Atas yang mempermudah akses dan informasi yang sesuai seperti jam keberangkatan dan juga waktu kereta datang.
\end{abstract}

\begin{abstract}
Based on data from PT Kereta Commuter Indonesia (KCI) the number of KRL passengers throughout 2017 reached 315.8 million passengers, up 12.55\% from the previous year and will experience an increase every year. With this amount it is known that commuting has also increased. Areas that have easy access to public and strategic transportation are in the center of Jakarta's business district, Dukuh Atas. Hamlet above is also an area with a large commuter population. Every day commuters in Indonesia spend 2-third of their time just waiting and there is repetition. this causes things such as the individual's lack of attention to health, social world and also a high level of stress. Therefore, with the increasing number of passengers and the appropriate area a third place can be created which is a place between the first place and second place that drives humans to build community, equality, and also routines in terms of something positive. For that, we need a place to stop in order to increase productivity and also eliminate the saturation that arises due to repetition that occurs. Then a place was built that had programs such as a bed, a place to chat and also a green room. This building also had room for ticket information that was integrated directly with the Upper Hamlet Station which facilitated access and information accordingly such as departure hours and also when trains arrived.
\end{abstract}




\section{PENDAHULUAN}

Kehidupan sekarang masyarakat pada zaman sekarang mengacu pada rutinitas sosial yang melibatkan 2 tempat yaitu first place $=$ tempat pertama atau rumah dan juga second place $=$ tempat kedua atau kantor / sekolah. Isu mengenai third place yang ditulis pada tahun 1990 oleh Ray Oldenburg ,berisi tentang bagaimana pembagian place, dimana manusia menjalani kehidupan sehari-hari, menjadi tiga kelompok yaitu first place, second place, dan third place. first place menurut Oldenburg adalah rumah, second place adalah tempat bekerja, dan third place adalah tempat bersantai dan bersosialisasi. Bagi masyarakat perkotaan yang umumnya bersifat individualis, third place menjadi semacam kebutuhan, dimana di tempat-tempat tersebut mereka memiliki kesempatan menikmati hubungan sosial dengan orang lain dalam suasana yang santai.

Penduduk, Laju, dan Kepadatan Penduduk Menurut Kabupaten/Kota, 2016-2017

\begin{tabular}{|c|c|c|c|c|c|c|}
\hline \multirow{2}{*}{ Kabupaten/Kota } & \multicolumn{2}{|c|}{ Penduduk } & \multicolumn{2}{|c|}{ Laju Pertumbuhan } & \multicolumn{2}{|c|}{ Kepadatan } \\
\hline & 2016 & 2017 & 2016 & 2017 & 2016 & 2017 \\
\hline Kepulauan Seribu & 23,616 & 23,897 & 1.18 & 1.19 & 2,714 & 2,747 \\
\hline Jakarta Selatan & $2,206,732$ & $2,226,830$ & 0.96 & 0.91 & 15,621 & 15,763 \\
\hline Jakarts Timsur & $2,868,910$ & $2,892,783$ & 0.88 & 0.83 & 15,258 & 15,385 \\
\hline Jakarta Pusat & 917,754 & 921,344 & 0.39 & 0.39 & 19,068 & 19,143 \\
\hline Jakarta Barat & $2,496,002$ & $2,528,065$ & 1.32 & 1.28 & 19,268 & 19,516 \\
\hline Jakarta Utara & $1,764,614$ & $1,781,316$ & 0.99 & 0.95 & 12,032 & 12,146 \\
\hline DXI JAKARTA & $0,277,628$ & $10,374,235$ & 0.98 & 0.94 & 15,517 & 15,663 \\
\hline
\end{tabular}

Sumber: Proyeksi Penduduk Sensus Penduduk 2010

Jakarta Dalam Angka, 2017

Gambar 4.1Sumber :https://tumoutounews.com

\section{Rumusan Masalah}

Tahap ini merupakan tahapan kedua, yaitu dengan merumuskan berbagai masalah tentang perancangan Third Place. Adapun rumusan masalahnya adalah bagaimana proyek Third Place dapat menjadi sebuah solusi dari permasalah para commuter?

\section{KAJIAN LITERATUR}

\section{The Great Good Place}

adalah buku karya Ray Oldenburg,1989. Buku ini dijadikan sebuah acuan untuk dijadikan suatu proyek third place. Oldenburg menyarankan bahwa untuk eksistensi yang sehat, warga negara harus hidup dalam keseimbangan tiga ranah: kehidupan rumah, tempat kerja, dan tempat-tempat yang bersosialisasi secara inklusif. First place adalah tempat manusia tinggal atau rumah, di first place, manusia mendapatkan pengalaman bersifat privat, karena privasi di tempat tinggal, dengan siapa Individu tinggal dan berbagai macam hal lainnya. Di tempat ini pun individu mendapat struktur dalam masing masing atau bisa dikatakan sebagai peran , siapa yang menjadi kepala keluarga, siapa peran anak berdasarkan keluarga, bagaimana memperlakukan orang yang lebih tua, apakah lebih segan berbicara dengan orang tua dan bagaimana perbedaan perbincangan berdasarkan hirearki yang ada pada orang tua dan bersama teman yang tentunya berbeda. Di tempat ini pun kebebasan berekspresi di limitasi, karena seperti hal nya keluarga.

Second place adalah tempat manusia melakukan pekerjaan untuk memenuhi kebutuhan sehari hari, salah satu ciri ciri tempat tersebut adalah terjadinya atasan-bawahan, siapa yang mempunyai pangkat lebih tinggi dalam pekerjaan, siapa yang menjadi pekerja baru dan juga 
pimpinan dalam perusahaan tersebut bisa dilihat di second place karena second place mempunyai pola terstruktur dalam suatu tempat ini. Tempat ini juga memungkinkan individu untuk mempunyai pengalaman sosial dimana pekerja melakukan perbincangan secara formal, tempat ini juga terorganisasi sebagai suatu tempat kerja, dan tempat ini selalu bersifat in hurry = selalu terburu-buru. Manusia sebagai mahluk sosial selalu membutuhkan interaksi sosial dengan sesamanya dalam daur hidupnya. Ruang publik telah menjadi latar bagi perkembangan kehidupan publik, baik dalam kegiatan ekonomi, sosial, hiburan, hingga politik.

Berlangsungnya kehidupan publik atau interaksi sosial sangat bergantung pada keberadaan dan perkembangan ruang publik. Minimnya ruang publik sebagai akibat pengembangan yang hanya berorientasi pada kepentingan kapital, mengakibatkan masyarakat mengatasinya secara mandiri. dan festival dan lain sebagainya.

Menurut pandangan Oldenburg, tempat ketiga dibagi menjadi 8 karakteristik :

- Tanah Netral

Pengguna third place tersebut bebas untuk keluar dan masuk sesuka hati mereka tanpa dipungut suatu bayaran dan kepentingan tertentu seperti bekerja di tempat itu.

- Level (Samarata)

Third place tidak mementingkan status sosial individu, semua umur, ras, agama, pekerjaan, tingkatan sosial, gender boleh datang ke tempat tersebut.

- Percakapan adalah aktivitas utama

Aktivitas utama pada third place adalah percakapan, percakapan yang santai, senang, tidak jarang disertai candaan. Percakapan merupakan aktivitas utama namun tidak hanya percakapan saja yang dilakukan dalam third place.

- Aksesibilitas dan akomodasi

Third place harus terbuka saat orang membutuhkannya. Tempat ketiga juga harus dapat mengakomodasi kemauan dari pengunjungnya.

- Pengunjung Tetap

Tempat ketiga memiliki pengunjung tetap. Pengunjung tetap secara tidak langsung juga memberikan warna dan juga menarik orang-orang baru untuk datang ketempat tersebut.

- Low Profile

Third places adalah tempat yang sehat. Di dalamnya tidak ada keborosan atau kemegahan dan cenderung berasa seperti rumah. Third places tidak pernah sombong atau penipu, ia menerima segala individu.

- Mood Menyenangkan (Playfull)

Mood yang ada pada third place adalah menyenangkan, hangat, dan nyaman. Tidak jarang dalam berinteraksi timbul canda dan tawa.

- Rumah jauh dari rumah

Pengunjung pada third place terkadang memiliki rasa kehangatan dan kepemilikan yang sama seperti mereka berada di rumahnya. Perasaan dimana mereka merupakan bagian dari tempat tersebut.

Rethinking Oldenburg: Third Places and Generation $Y$ in a Developing Country Context

Sebuah paper karya Dosen University of West Indies Bernama Anne P. Crick yang mendapat gelar best paper award pada tahun 2011. Dalam penulisan,beliau menulis bahwa beliau menyesali karena pada kenyataan berkehidupan, banyak individu yang belum sadar akan pentingnya third place dan juga tempat ketiga belum sepenuhnya diakui. Bahkan sewaktu teori Oldenburg mengalami kemunduran, banyak tempat komersial yang memanfaatkan konsep third place dan memasarkan diri mereka sebagai tempat ketiga.Telah banyak studi mengenai third place namun 
terjadi keterbatasan analisa bagaimana cara third place menarik bagi suatu komunitas.(Mikunda 2004) menyatakan bahwa generasi Y (millenials) akan lebih tertarik dengan third place versi digital melainkan third place versi Oldenburg.dalam teori ini juga disebutkan bahwa Oldenburg memfokuskan penelitian tentang Third Place di Amerika dan Eropa, sangat memungkinkan jika negara maju sangat membutuhkan third place yang berbeda dari negara berkembang. Oldenburg bercerita tentang third place yang menjadi ruang di antara first place dan second place,namun orang menjadi terlalu tergantung kepada kedua tempat ini yakni tempat tinggal dan juga tempat kerja. Terjadinya Rat Race, pola hidup dan kesamaan adalah hal yang terjadi dalam kehidupan bermasyarakat ini.

Rat Race adalah suatu pengejaran sesuatu tanpa henti, tetapi tidak mendapatkan hasil. Di dalam pengertian finance, pengejaran tersebut merupakan penyeimbangan antara pendapatan dengan biaya. Any place can be a third place and Oldenburg describes restaurants, bookstores, coffee shops, photoshops and gyms which fit his definition of third places. They are third places not necessarily by design, but because they are comfortable places for people to congregate and find their home away from home (Oldenburg, 2002).

Crick menyebutkan bahwa dalam hal ini, peluang untuk berinteraksi di era digital sangat beragam. Steinkuhler and Williams menyebutkan bahwa bahwa bermain game online memiliki potensi untuk menyediakan ruang untuk interaksi sosial dan hubungan di luar sekolah, pekerjaan atau rumah.Tempat ketiga virtual juga mengatasi keterbatasan waktu dan ruang ,dan juga lebih mudah untuk diakses jika dibandingkan dengan tempa ketiga berupa fisik. Third place Oldenburg dinyatakan telah berkembang secara spontan dan dimanfaatkan oleh suatu tempat usaha seperti Starbucks yang sengaja dirancang untuk menarik orang-orang yang membutuhkan tempat ketiga dan juga sebagai tempat yang berbeda dari yang lain. Organisasi decava ( 2006 ) juga memperkirakan bahwa semakin banyak Kinkos Generation maka semakin banyak juga permintaan akan Third place ini.

Kinkos Generation merupakan platform yang mengutamakan konsep kerja darimana saja selain rumah ataupun kantor, sama halnya dengan remote working.

\section{METODE}

\section{Pencarian dan Pengolahan Data}

Pencarian dan pengolahan data dapat digolongkan dalam dua kategori, yaitu: data primer dan data sekunder. Data primer yaitu data yang diporoleh langsung dari sumbernya. Sedangkan data sekunder yaitu data yang diperoleh secara tidak langsung dari sumbernya, atau data yang diperoleh dari bahan-bahan kepustakaan. Dalam pencarian data dari informasi primer dan sekunder, digunakan metode yang dapat dijelaskan sebagai berikut, yaitu:

\section{Data Primer}

Observasi

Observasi adalah suatu kegiatan yang dilakukan dengan mengamati dan mencatat secara sistematis terhadap gejala atau fenomena yang diselidiki. metode observasi dapat diartikan sebagai pencatatan sistematika lapangan yang diselidiki. Dengan melakukan observasi akan mendapatkan data atau informasi-informasi yang berkaitan dengan perkantoran dan lapisan masyarakat.

\section{Wawancara / Depth Interview}

Wawancara merupakan suatu kegiatan yang dilakukan dengan cara bertanya langsung kepada pihak yang terlibat (sumber). Berikut merupakan adapun daftar pertanyaan yang diajukan antara lain: 
a. Dimana Bapak/lbu bekerja dan tinggal?

b. Apakah Bapak sering menggunakan transportasi umum untuk pergi bekerja?

c. Bagaimana pendapat Bapak/lbu pulang pergi dengan menggunakan transportasi umum?

d. Bagaimana pendapat Bapak/ Ibu jika terdapat tempat untuk beristirahat dan memiliki berbagai fasilitas di dekat area transportasi umum?

e. Apa saja fasilitas yang diharapkan ada pada tempat tersebut?

Dengan adanya wawancara ini, dapat menjadi sebuah acuan dalam menentukan program untuk perancangan third place. Selain itu, dengan melakukan depth interview ini dapat melihat masalah yang sering terjadi dan solusi apa yang dapat dibuat.

\section{Data Sekunder}

Data sekunder yaitu data atau informasi yang tidak berkaitan secara langsung dengan obyek perancangan tetapi sangat mendukung program perancangan. Data yang dapat digunakan yaitu data dari studi pustaka seperti baik dari teori, pendapat ahli, serta peraturan dan kebijakan pemerintah yang dapat dijadikan dasar perencanaan sehingga dapat memperdalam analisa. Berikut data yang diperoleh dari penelusuran literatur bersumber dari data internet dan buku.

a. Data atau literatur tentang tapak terpilih berupa peta wilayah, dan potensi alam dan buatan yang ada di kawasan. Data ini selanjutnya digunakan untuk menganalisis kawasan tapak;

b. Literatur tentang bangunan dengan tema Open Architecture for the third place yang meliput fungsi, fasilitas dan ruang-ruang yang mewadahinya

Dalam perancangan bangunan Third Place di daerah Dukuh Atas ini menggunakan metode deskriptif analisis, pengertian deskriptif analisis adalah suatu metode yang merupakan paparan atau deskripsi atas fenomena yang terjadi. Analisis kualitatif adalah analisis dengan cara mengumpulkan data berupa cerita rinci atau keadaan sebenarnya. Untuk mendapatkan data dan informasi yang berhubungan dengan obyek rancangan perlu mengikuti langkah-langkah yang meliputi beberapa tahap sebagai berikut:

\section{Ide Perancangan}

Proses dan tahapan kajian yang digunakan dalam perancangan Bangunan Third Place, dijelaskan sebagai berikut:

a. Pencarian ide atau gagasan dengan menyesuaikan informasi tentang third place yang berada di tengah kota .

b. Pemantapan ide perancangan bangunan Third Place melalui penelusuran informasi dan data-data arsitektural maupun non- arsitektural dari berbagai pustaka dan media sebagai bahan perbandingan dalam pemecahan masalah.

\section{Analisis Perancangan}

Berdasarkan survei Euromonitor International, Jakarta akan menjadi kota paling padat di dunia pada 2030. Populasi di Jakarta yang mencapai 35,6 juta jiwa diperkirakan akan bertambah 4,1 juta orang antara 2017-2030. Jakarta yang merupakan ibukota negara Indonesia dengan kepadatan tertinggi di Indonesia, yang juga masuk dalam jajaran 10 Besar kota terpadat di dunia. Jakarta sendiri terbagi lagi menjadi 6 Kota Madya, berdasarkan jumlah penduduk Jakarta Barat menempati peringkat kedua setelah Jakarta Timur namun Jakarta Timur memiliki luasan 1,5 kali lipat dari Jakarta Barat, dari segi kepadatan Jakarta barat juga menempati peringkat kedua setelah Jakarta Pusat. Bisa dilihat pada data Jakarta Pusat bahwa pada tahun 2016 - 2017, jumlah penduduk dan kepadatan penduduknya yaitu 19.068 dengan jumlah penduduk 917.754. Sedangkan pada tempat lain seperti Jakarta Selatan yang memiliki kepadatan 15.621 , jumlah penduduknya yaitu 2.206 .732 . Hal ini menandakan bahwa kepadatan yang terjadi pada Jakarta 
Pusat biasanya didapat dari berbagai warga commuter, karena pada dasarnya di daerah Jakarta Pusat merupakan terjadinya pusat pemerintahan dan pusat ekonomi perkantoran .

setiap hari kaum komuter di Indonesia menghabiskan waktu di luar rumah hampir 2/3 waktu mereka. Ada juga waktu yang hilang untuk menunggu saat perpindahan, pengulangan yang terjadi menimbulkan kejenuhan dan masalah lain

a. jumlah komuter di Jakarta pada tahun 2019 mencapai 2,42 juta

b. survey margin error menunjukkan rata rata masyarakat Jakarta di kala macet menghabiskan 1.5 jam per hari

c. total waktu yang dihabiskan warga Jakarta untuk bolak balik antar rumah mencapai 3,63 juta jam per hari

\section{SWOT}

a. STRENGTH Tapak terletak di tengah kota, dikelilingi oleh Arteri Sudirman yang merupakan pusat perkantoran di daerah Jakarta

b. WEAKNESS Jalan sekitar tapak relatif sempit, kemacetan dan keramaian yang terjadi sampai terjadi penumpukan. Daerah untuk menunggu juga hanya trotoar kecil

c. OPPORTUNITY Terdapat PKL yang berdagang di trotoar, Beberapa daerah sekitar juga tidak boleh dilalui kendaraan bermotor.

d. THREAT Daerah terbuka dalam bangunan bisa menjadi sarana negatif jika tidak diatur dengan baik.

\section{POINTS OF INTEREST}

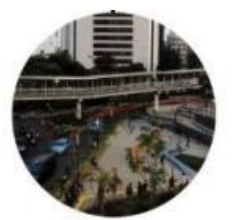

spot budaya dukuh atas awalnya berfungsi sebagai trotoar namun dijadikan area untuk memfasilitasi kegiatan warga seperti berbagai olahraga, bersekspresi dan juga berkegiatan. Hal ini juga mendukung beberapa aspek dalam tempat singgah seperti kebiasaan berjalan kaki dan penambahan community space di dalam tapak

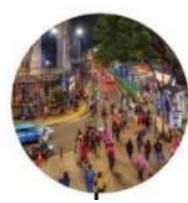

dukuh atas menjadi kawasan pertama yang berorientasi transit dengan 7 transportasi umum berbeda seperti BRT,MRT,LRT . kereta bandara, kereta commuter, dan juga bis. kawasan ini dibuat menjadi kawasan pejalan kaki yang ramah lingkungan. Hal ini juga merupakan aspek utama dalam pembangunan tempat singgah di Dukuh Atas

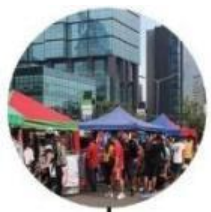

kawasan dipenuhi dengan pedagang kaki lima yang terdapat di sekitar bahu jalan maupun jalan biasa. Maka itu PKL akan dipindahkan ke dalam Program dalam halnya saling mendukung keberadaan program dan proyek

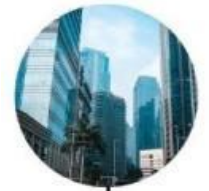

kawasan dukuh atas diapit oleh jalan arteri Sudirman yang dikelilingi oleh perkantoran dan menjadi pusat perkantoran di sekelilingnya. Pekerja ini merupakan pengguna tetap dari tempat singgah dukuh atas

rata rata commuter menghabiskan $1 / 3$ harinya untuk menunggu, dan ada waktu yang terbuang setiap harinya. membutuhkan tempat untuk singgah sementara.untuk beristirah 
ANALISA PENGGUNA

Sebagai kawasan berbasis TOD maka kawasan ini direncanakan untuk menjadi suatu titik pertemuan berbagai ragam transportasi seperti
a. komuter/ dalam kota (0.5 jam - 2 jam perjalanan)
b. komuter/ antar kota (2-3 jam perjalanan)
c. turis/dari arah bandara
d. pengguna tidak tetap
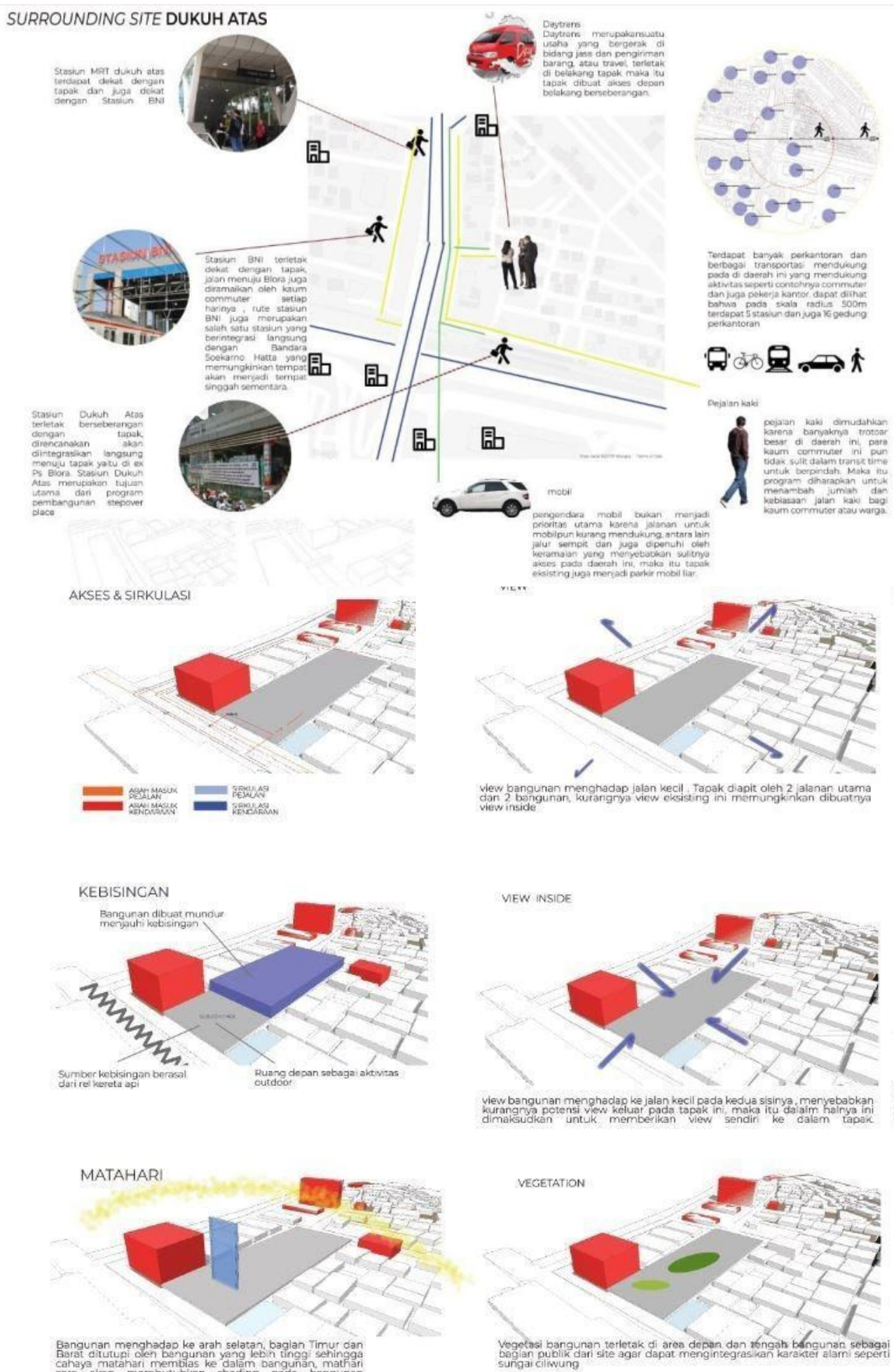

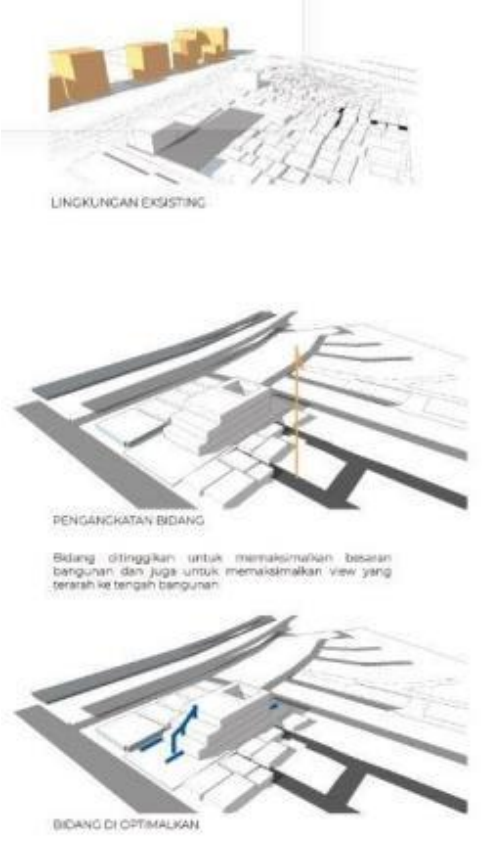

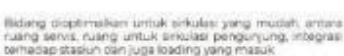

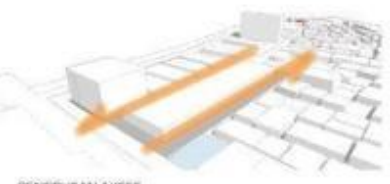

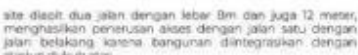
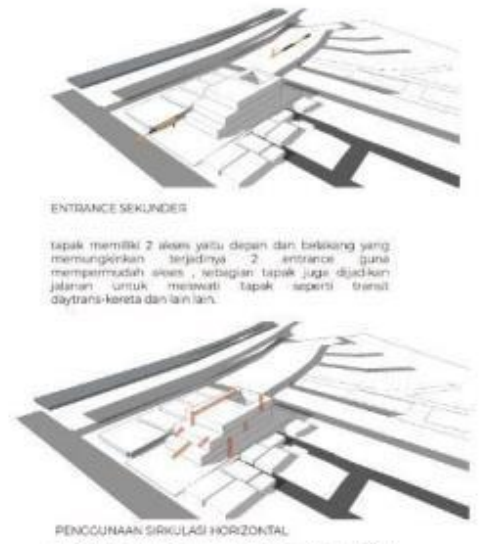

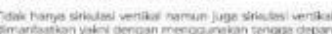

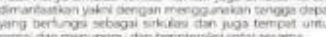

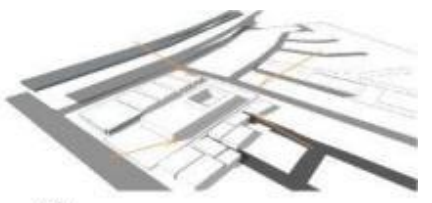

vew
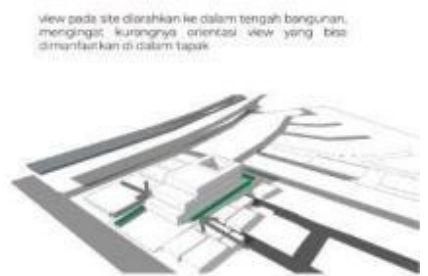

nunse uns

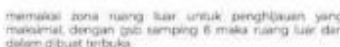

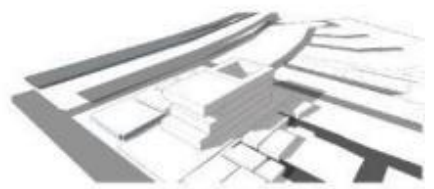

RaNCLNCN

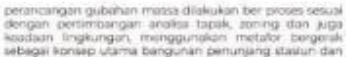

\section{DISKUSI DAN HASIL}

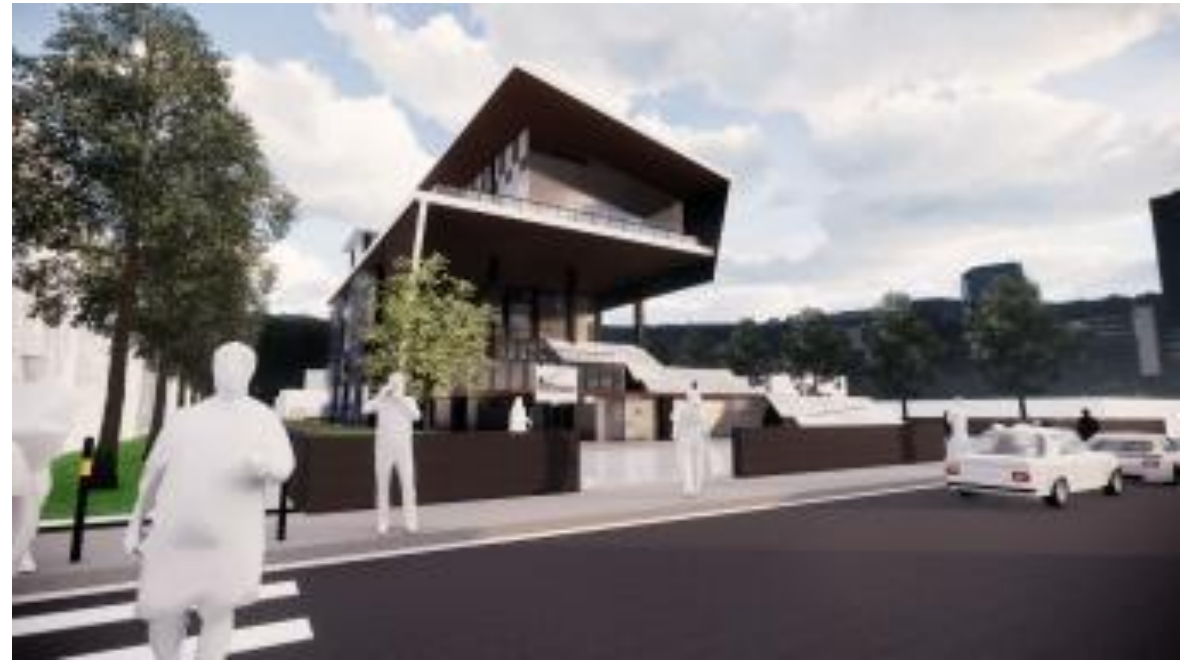

Konsep utama bangunan yaitu 'bergerak' sama seperti manusia dan kaum komuter yang terus bergerak agar mencapai tujuan, seperti bangunan integrasi yaitu stasiun Dukuh Atas yang menjadi tempat utama sebuah transportasi kereta yang bergerak.

\section{a. Singgah}

Membuat sebuah bangunan dengan konsep tempat singgah sementara bagi para kaum komuter maupun rekreasi warga sekitar

b. Alam

Menciptakan suatu karakter alami sendiri dengan mengintegrasikan kali ciliwung dengan air terjun dan juga penghijauan 


\section{c. Karakter Unik}

Menciptakan suatu Fasad yang berintegrasi langsung dengan logo commuter line

d. Penyediaan Ruang Publik

Menyediakan berbagai kebutuhan Ruang Publik untuk warga sekitar maupun komuter sebagai sarana Interaksi sesama ( $3 r d$ place)

e. Penyediaan Kebutuhan Komuter

Menyediakan berbagai kebutuhan sehari- hari para kaum komuter yang pada dasarnya membutuhkan

\section{f. Ruang Gerak Efektif}

Sirkulasi di luar dan dalam bangunan memicu mobilisasi yang baik ,teratur dan juga tujuan yang jelas

\section{PROGRAM UTAMA}
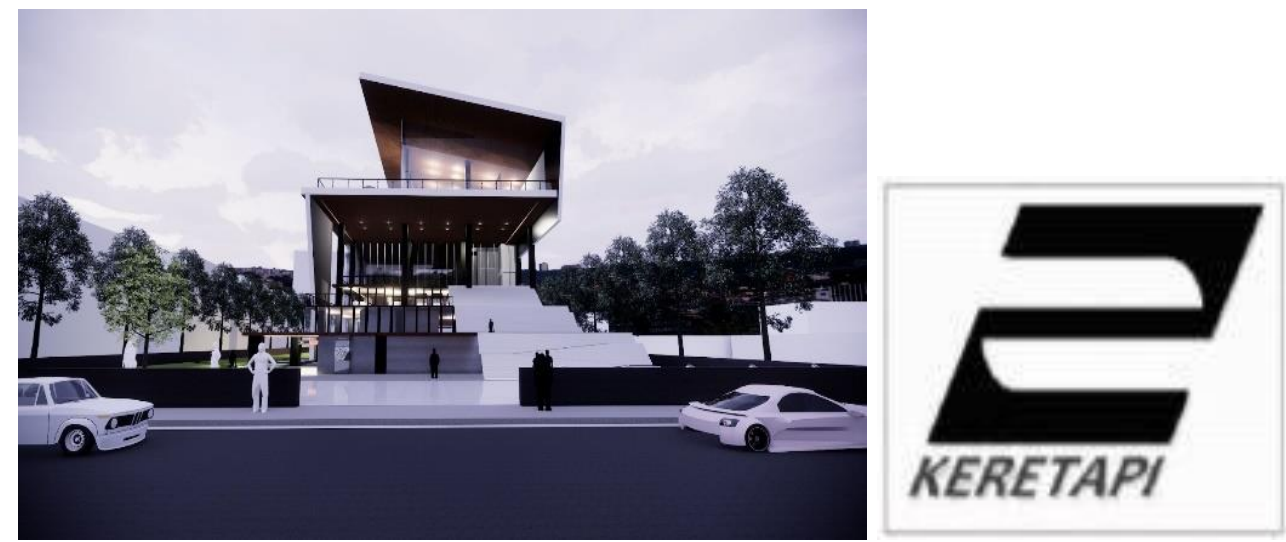

Tampak bangunan dibuat seperti logo KRL untuk mendukung integrasi dari Stasiun Dukuh Atas di sebrangnya.

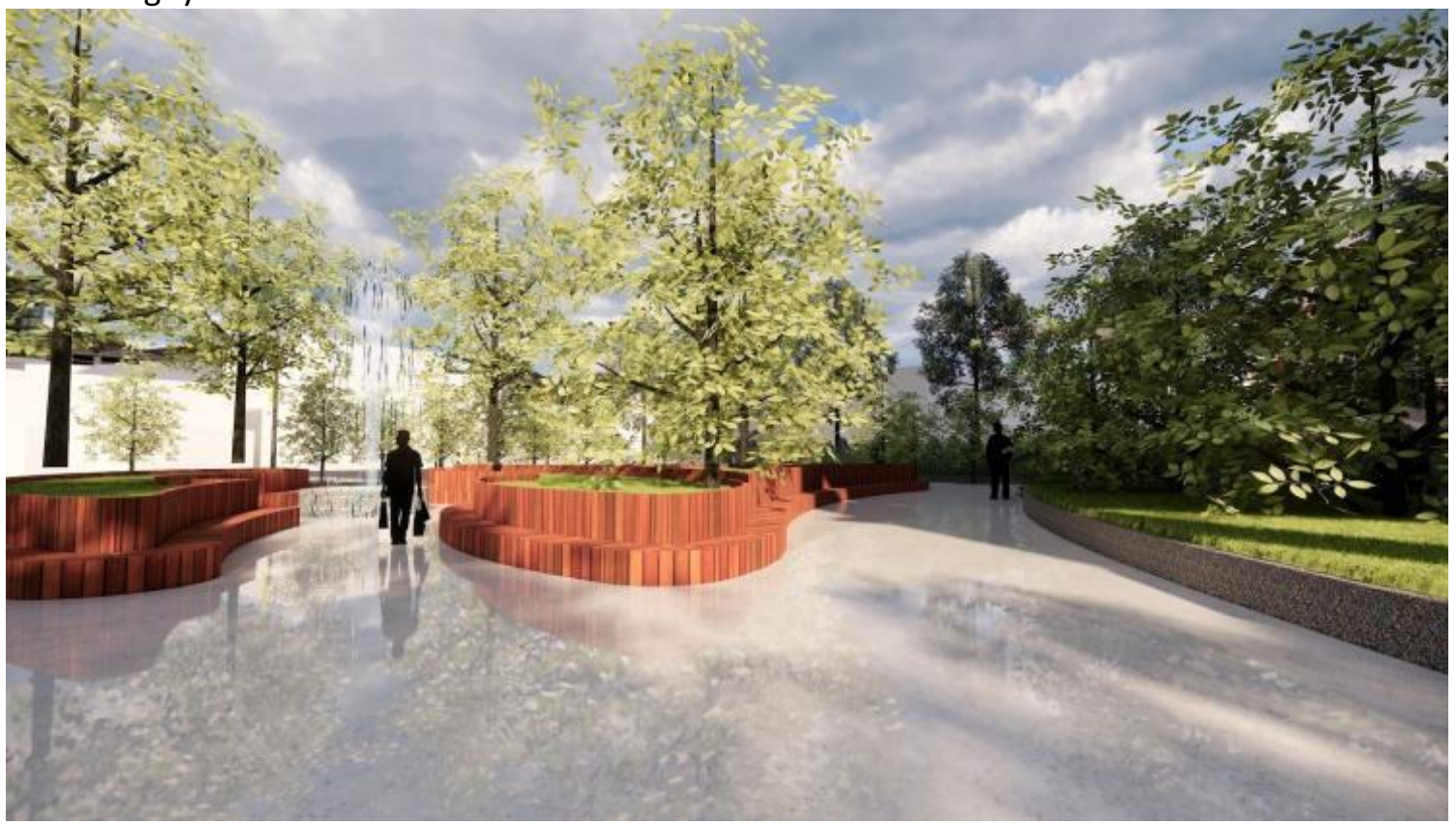

adanya taman di belakang sebagai area kumpul para kaum Commuter yang ingin beristirahat, bercengkrama atas sesama, dan juga menghilangkan kejenuhan. 


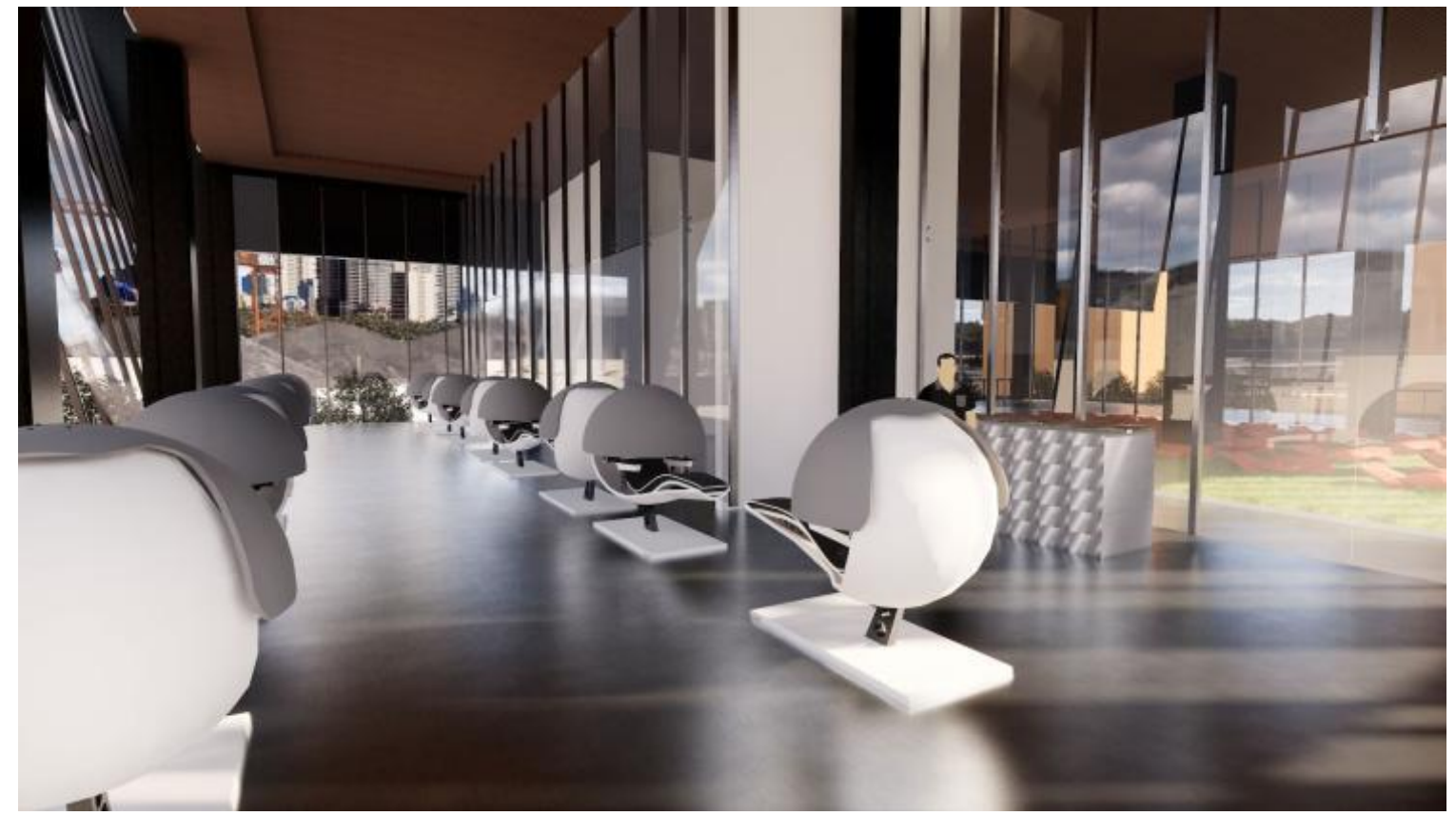

Sleeping Pods sebagai area sewa tidur per-jam yang biasanya ada di tempat seperti Bandara ini memang ditujukan untuk area pengguna untuk tidur dan juga beristirahat menghabiskan waktu. Area retail dipadukan dengan ruang luar dan hanya dibatasi oleh dinding berupa air terjun untuk menyejukkan dan cenderung membuat suasana menjadi lebih sejuk.

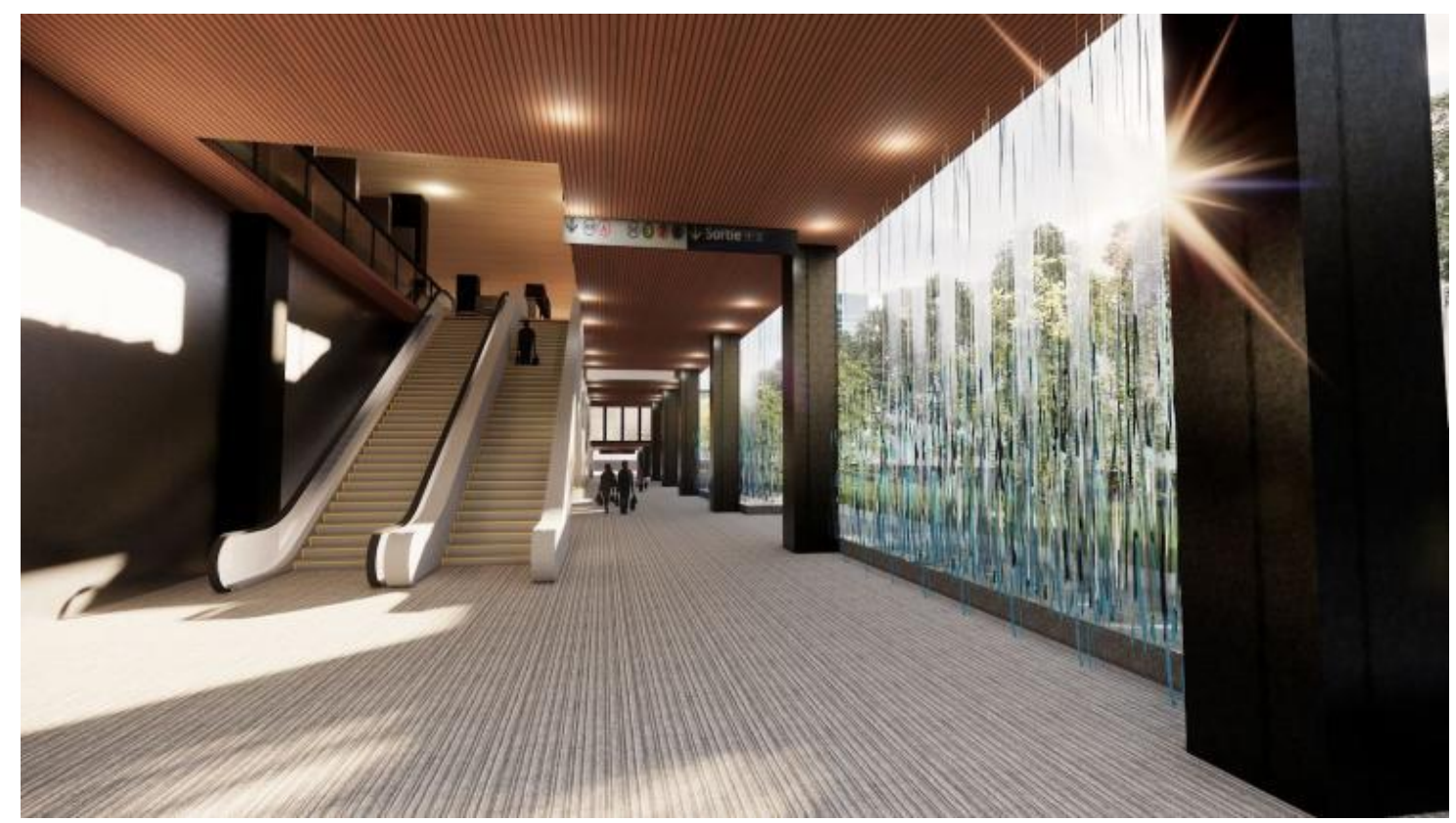




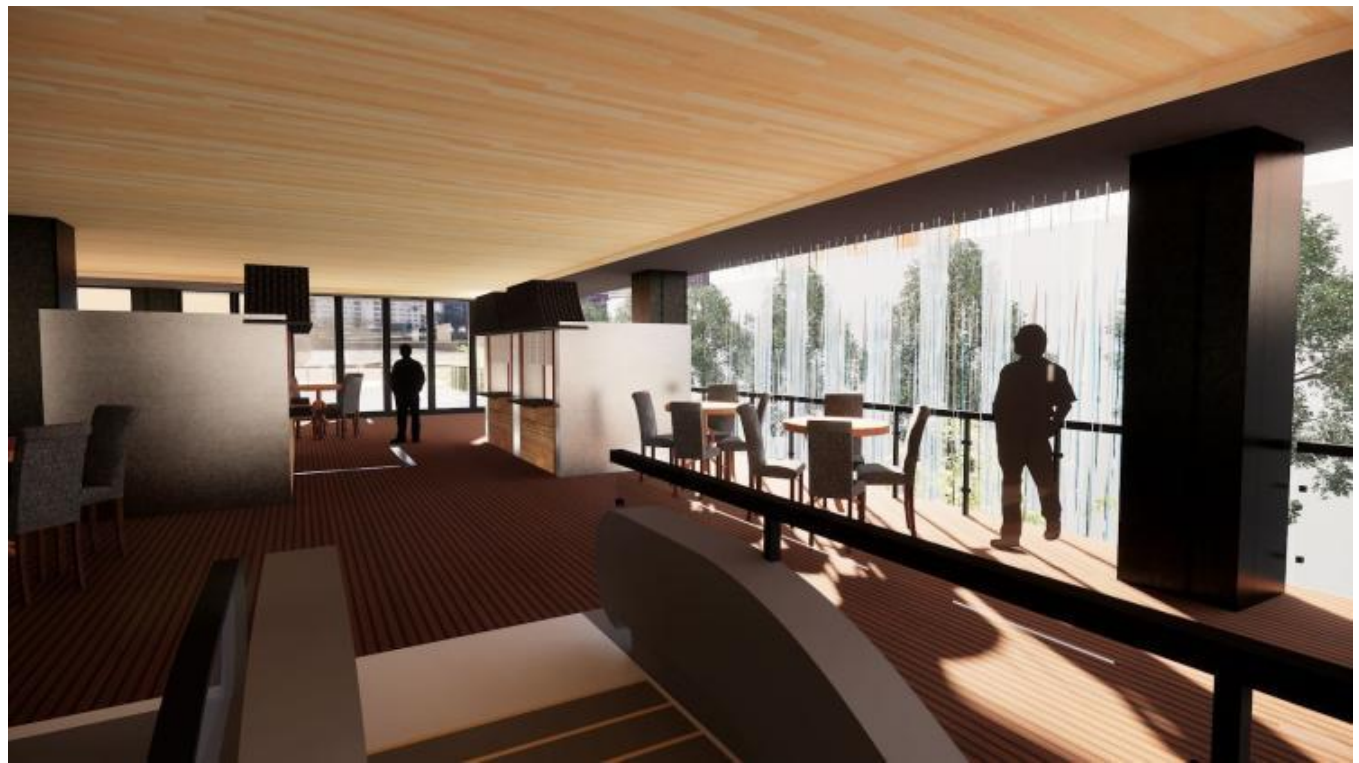

Area foodcourt mempunyai view langsung ke belakang dan juga ke samping yaitu taman dan area air terjun guna membuat bangunan mempunyai view ke dalam yang indah.

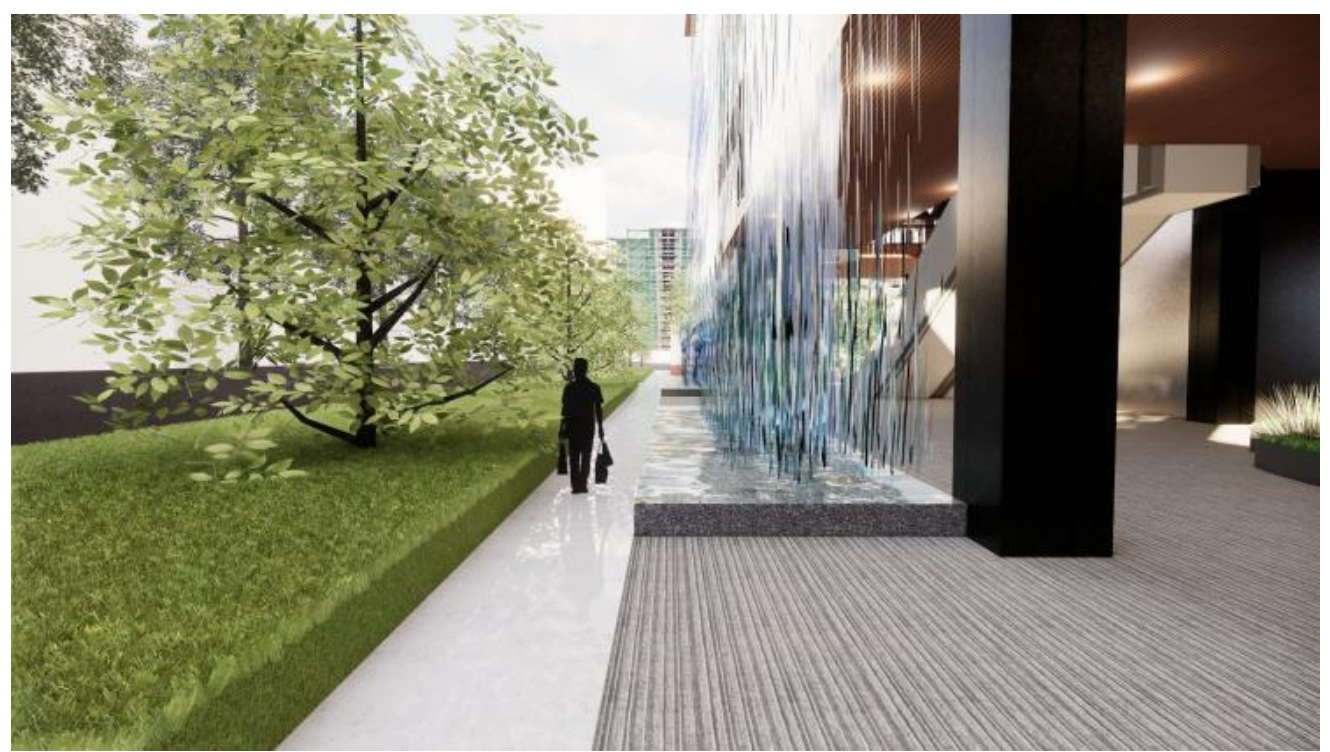

area masuk tapak bisa melalui jalan samping dengan taman di sebelah kiri mengingat Garis Sempadan Jalan yang cukup lebar yaitu $6 \mathrm{~m}$. Penggunaan taman di bagian samping juga didukung dengan suasana air yang membantu menjadi objek hiburan bagi para pengunjung.

\section{KESIMPULAN DAN SARAN}

Berdasarkan dari data diatas dapat disimpulkan bahwa Dukuh Atas merupakan tempat yang cocok untuk third place bagi commuter dikarenakan karena Dukuh Atas merupakan daerah TOD yang strategis dan juga merupakan tempat dengan mobilitas tinggi.

a. Dari berbagai proyek literatur dan juga kajian teori dapat dilihat bahwa sebagian bangunan third place masing masing mengelompokkan dari 8 akses, ada segi ruang berbayar dan juga segi ruang yang gratis .

b. Suatu tempat dapat dikatakan sebagai tempat ketiga bila, didalamnya ada orang berkumpul saling berinteraksi satu dengan yang lain,gratis dan juga untuk semua orang.

c. Sesuai dengan kajian teori tentang Oldenburg dan juga A.P Crick, third place tidak ditujukan hanya untuk tempat tradisional/ruang melainkan bisa saja mengenai digitak/virtual 


\section{DAFTAR PUSTAKA}

Baskoro, R. (2018). Bekas Pasar Blora Tak Bisa Dijadikan Tempat Parkir Lagi, Dishub Kebingungan Cari Penggantinya. Retrieved from cari-penggantinya.

Baskoro, R. (2018). Lahan Parkir Bekas Pasar Blora Tak Bisa Digunakan Lagi,. Retrieved from https://wartakota.tribunnews.com/2018/01/25/

Schulz, C., N. (2010). Genius loci: towards a phenomenology of architecture.

Academy Editions, 1980

Country C. (2011). International CHRIE Conference-Refereed Track. 7

Crick, A. P. (2011). Rethinking Oldenburg: Third Places and Generation Y in a Developing

Oldenburg, R. (1989). The Great Good Place . USA: Da Capo Press

Theo (2019). Belum Ada Lahan Parkir, Lahan Bekas Pasar Blora Dikuasai Warga,. Belum Ada Lahan Parkir, Wartakotalive 